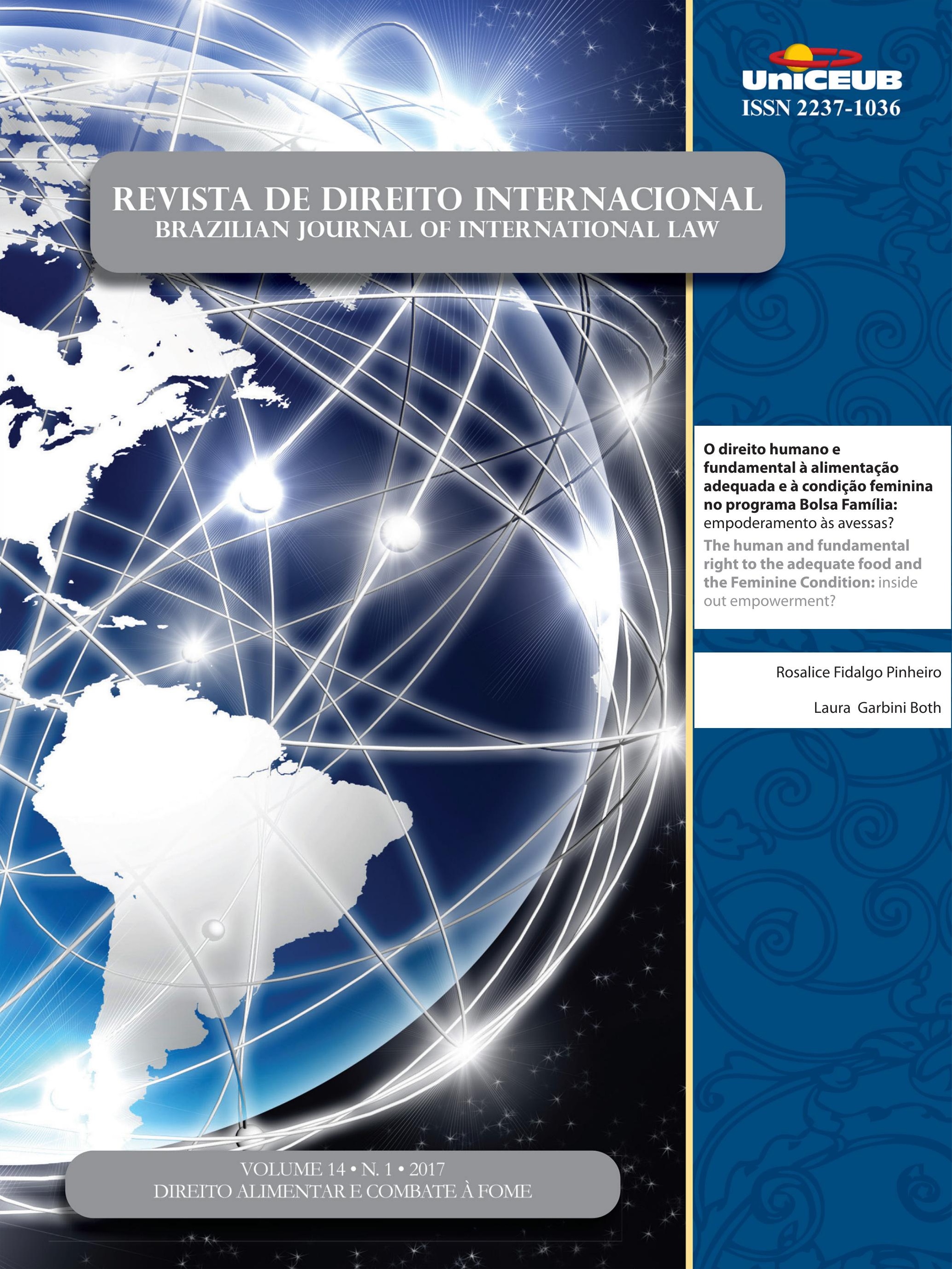




\section{Sumário}

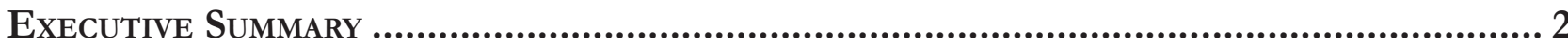

Daniel Balaban

Crônicas Sobre o Direito Alimentar e o Combate À Fome .............................................. 5

South-South Food and Nutrition Security promotion: the Brazilian experience

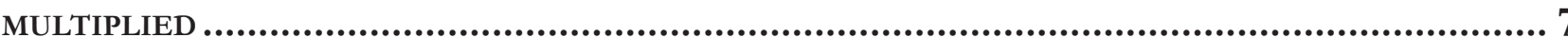

João Almino

Access to Food as a Human Right: Brazil, WFP and South-South Cooperation .......10 Carlos R. S. Milani

Dossiê temático: Direito Alimentar e Combate à Fome 13

WFP'S ROLE IN BUILDING SUSTAINABLE BRIDGES BETWEEN THE RIGHT TO ADEQUATE FOOD AND THE FREEDOM FROM HUNGER 15

Christiani Amaral Buani e Bruno Valim Magalhães

Direito humano À ALIMENTAÇÃo, (IN) SEgURANÇA ALIMENTAR E DESENVOLVIMENTO: OS DESAFios à REALIZAÇão PROGRESSIVA Na AMÉrica LATINa

Sinara Camera e Rubia Wegner

STATE'S INTERNATIONAL RESPONSIBILITY FOR THE HUMAN RIGHT TO FOOD: IMPLEMENTATION IN BRAZIL THROUGH AGROECOLOGY

Paula F. Strakos e Michelle B.B. Sanches

NegotiatiNg agRiCULtURE IN THE WORLD TRADE ORgANIZATION: FOOD SECURITY AS A NON-TRADE CONCERN.

Ana Luísa Soares Peres e Letícia de Souza Daibert

QUANDO HABITAR CORRESPONDE AO DIREITO HUMANO À ALIMENTAÇÃO

Fernanda Viegas Reichardt e Maria Elisa de Paula Eduardo Garavello 
The ROLE OF SUSTAINABLE LEARNING POLICIES ON THE FIGHT AGAINST

HUNGER IN ADULT EDUCATION.

Hiran Catuninho Azevedo

O DIREITO HUMANO E FUNDAMENTAL À ALIMENTAÇÃo ADEQUADA E À CONDIÇÃo

FEMININA NO PROGRAMA BOLSA FAMÍlIA: EMPODERAMENTO ÀS AVESSAS?

Rosalice Fidalgo Pinheiro e Laura Garbini Both

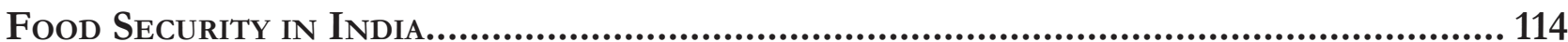

Ranjana Ferrão

SEguranÇA ALIMENTAR E A GOVERnANÇA ECONÔMICA GLOBAL

Danielle Mendes Thame Denny, Douglas de Castro, Alexandre Ricardo Machado, José Valverde Machado Filho e Gabrielle Fontes Witt

Outros Artigos.

The legal implications of the Draft Universal Declaration of the Rights of MANKIND

Catherine Le Bris

Litigating Indigenous Dispossession in THE Global Economy:

Law's Promises and Pitfalls................................................................................ 165

Charis Kamphuis

UNE DÉFINITION DU PRÉ-INVESTISSEMENT CONFORME À L'APPROCHE FRANÇAIS MAIS CONTRAIRE À L'APPROCHE AMÉRICAINE AU SEIN DES TRAITÉS BILATÉRAUX D'INVESTISSEMENTS IRANIENS

Peyman Dadras

CONFLITOS ENTRE REGULAÇÕES INTERNAS RELATIVAS À INTERNET E O DIREITO DO COMÉRCIO INTERNACIONAL: O PAPEL DA OMC PERANTE O SISTEMA DE COMPUTAÇÃO DA NUVEM ............238

Alice Rocha da Silva e Filipe Rocha Martins Soares

Prélèvement: origem, EVoluÇão e ocaso do Privilégio NAS SuCESSÕes INTERNACIONAIS NA FRANÇA

Fernando Pedro Meinero 
OS CONTRATOS INTERNACIONAIS DE FINANCIAMENTO E O CENTRO FINANCEIRO DE

Nova IorQue: CONSIDERAÇões SOBRE A AUTONOMIA DA VONTADE

Fernanda Torres Volpon

Mercosul e o Meio ambiente: ANÁlise da tUTELA REgional AMBIENTAL 284 Clarissa Ferreira Macedo D'Isep

Ainda (E uma Vez MAis) o SILÊNCIO QUe ENTOA O TRIUNFo De Lewis Carrol: A Regra N ${ }^{\circ} 42$ do Supremo Tribunal Federal

Thiago Aguiar Pádua e Bruno Amaral Machado

\section{A Natureza Jurídica do Sistema de Solução de Controvérsias da OMC} E DE SuAs Decisões: Solucionando um Imbróglio 316

Camila Capucio

Brics: Desafios do DESENVOLVIMENTO ECONÔMICO E SOCIOAMBIENTAI Magno Federici Gomes e Luís Eduardo Gomes Silva

REVER OU ROMPER COM VESTFÁLIA? POR UMA RELEITURA DA EFETIVA CONTRIBUIÇÃO DOS ACORDOS DE PAZ DE 1648 À CONSTRUÇÀO DO MODELO VESTFALIANO DE ESTADOS.

Luiz Magno Pinto Bastos Junior

Justiça de Transição EM SUA GÊNESE: A Alemanha Pós-NAZismo 378 Bruno Galindo

Quando JUlgar SE TORNa UM ESPETÁCulo: A INTERAÇão ENTRE o Supremo Tribunal Federal e a opinião pública, A PARTIR de REFlexões da LITERATURA ESTRANGEIRA

Patrícia Perrone Campos Mello

TolerânCia E refugio: um ENSAIO A PARTIR do ACORdo EU-TurQuia 425 Flávia Cristina Piovesan e Ana Carolina Lopes Olsen 


\title{
0 direito humano e fundamental à alimentação adequada e à condição feminina no programa Bolsa Família: empoderamento às avessas?*
}

\author{
The human and fundamental right to the \\ adequate food and the Feminine Condition: \\ inside out empowerment?
}

\author{
Rosalice Fidalgo Pinheiro** \\ Laura Garbini Both***
}

\section{Resumo}

O objetivo deste trabalho é examinar a condição feminina em políticas públicas de efetivação do direito humano e fundamental à alimentação adequada. Considerando-se as políticas públicas de segurança alimentar e nutricional como políticas públicas em favor da família, a condição feminina encontrou destaque no Programa Bolsa Família por estabelecer a mulher como principal beneficiária. Enquanto alguns sinalizam uma perda de sua autonomia em face do mercado de trabalho, outros reconhecem o fortalecimento de seu papel na família. Conclui-se pela melhora da condição feminina, em razão do alto percentual de famílias monoparentais cujas responsáveis são mulheres. Eis o aspecto que guarda originalidade no trabalho: indagar pelo empoderamento às avessas das beneficiárias do Programa. Para realizar esta análise, o trabalho utilizou-se do método dedutivo, e dos procedimentos de pesquisa empírico e bibliográfico. Os marcos teóricos que nortearam a discussão contemplam as obras de Joaquín Herrera Flores, Bila Sorj e Andrea Gama e Nancy Fraser. O plano de trabalho foi divido em três partes: (i) a afirmação do direito humano à alimentação no plano internacional; (ii) sua recepção no plano constitucional e as políticas públicas de segurança alimentar e nutricional; (iii) a condição feminina no Programa Bolsa Família.

Palavras-chave: Direito humano e fundamental à alimentação adequada. Segurança alimentar e nutricional. Políticas públicas. Família. Condição feminina. Programa Bolsa Família. Mestrado em Direitos Fundamentais e Democracia do Centro Universitário Autônomo do Brasil (UniBrasil).E-mail: rosallice@gmail.com

*** Doutora em Educação junto ao Programa de Pós-Graduação em Educação da Pontifícia Universidade Católica do Paraná (PUCPR) e Mestre em Antropologia Social junto ao Programa de Pós-Graduação em Antropologia Social da Universidade Federal do Paraná (UFPR). Professora do Programa de Mestrado em Direitos Fundamentais e Democracia do Centro Universitário Autônomo do Brasil (UniBrasil). E-mail: laura.both@unibrasil.com.br

\section{Abstract}

The study aims to examine the status of women in public policy implementation of the human and fundamental rights to adequate food. Considering the public policy of food security and nutrition and public policies for the family, the status of women found prominence in the Family Allowance Program by establishing the woman as the main beneficiary. While some signal a loss of women's autonomy in the face of the labor market, others 
recognize the strengthening of their role in the family. The results confirmed the improvement of women's status, because of the high percentage of single-parent families whose heads are women. This is the aspect that keeps originality at work: ask the empowerment inside out of the Program beneficiaries. To perform this analysis we used the deductive method and empirical and bibliographic research procedures. The theoretical frameworks that guided the discussion include the works of Joaquín Herrera Flores, Bila Sorj and Andrea Gama and Nancy Fraser. The work plan was divided into three parts: (i) the affirmation of the human right to food at international scope; (Ii) receipt at the constitutional level and the public policies for food and nutrition security; (Iii) the status of women in the Family Allowance Program.

Keywords: Human and fundamental right to adequate food. Food and nutrition security. Public policy. Family. Womanhood; Bolsa Família Program.

\section{INTRODUÇÃo}

A fome e a subnutrição são fenômenos antigos, sendo possível observá-los não apenas em regiões geográficas específicas como a África ou em países devastados pela guerra, mas em países com grandes reservas naturais como o Brasil. Josué de Castro, em sua obra clássica "Geografia da fome", já caracterizava a fome coletiva como um fenômeno social geograficamente universal, a ponto de afirmar que "toda a terra dos homens tem sido também até hoje a terra da fome" ${ }^{1}$. Paradoxalmente, o direito humano e fundamental à alimentação é um direito relativamente novo ${ }^{2}$. Embora já tenha sido afirmado no plano internacional, na Declaração de Direitos Humanos de 1948 e no Pacto Internacional de Direitos Econômicos, Sociais e Culturais de 1966, somente foi recepcionado por um número restrito de Constituições,

1 CASTRO, Josué de. Geografia da fome (O dilema brasileiro: pão ou aço). 10. ed. Rio de Janeiro: Antares, 1984. p. 48.

2 COURTIS, Christian. The Right to Food as a Justiciable Right: Challenges and Strategies. BONGDANDY, A. WOLFRUM, R. (Coord.). Max Planck Yearbook of United Nations Law. Local: Koninklije Brill N., 2007. p. 323; NIVARD, Carole. Le droit à l'alimentation. La Revue des Droits de l'Homme, jun. 2012. Disponível em: <http:// revdh.files.wordpress.com/2012/06/le-droit-c3a0-lalimentation. pdf>. Acesso em: 06 out. 2016. Disponível em: <http://revdh.files. wordpress.com/2012/06/le-droit-c3a0-lalimentation.pdf>. Acesso em: 06 out. 2016. p. 1. ingressando, tardiamente, na Constituição brasileira, por meio da Emenda Constitucional no 64/2010.

Trata-se, ainda, de um fenômeno que decorre de injustiças sociais, exclusões políticas ou econômicas e discriminações ${ }^{3}$. Nesse contexto de exclusão, o direito humano e fundamental à alimentação foi afirmado no plano internacional, em meio ao embate entre universalismo e relativismo, e recepcionado como direito fundamental social na Constituição da República. Para tanto, editou-se a Lei no 11.346/2006, denominada de Lei Orgânica de Segurança Alimentar e Nutricional (LOSAN), que estabeleceu, em seu artigo $1^{\circ}$, o dever do Estado formular e implementar políticas, planos e ações para assegurar aquele direito. É imprescindível que, na formulação dessas políticas públicas, inclua-se a questão de gênero, com vistas a realizar a segurança alimentar e nutricional em favor da família.

Delineia-se, então, o objeto deste trabalho que é contrapor o direito humano e fundamental à alimentação adequada à condição feminina ${ }^{4}$. Considerando-se as políticas públicas de segurança alimentar e nutricional como políticas públicas em favor da família, propõe-se uma difícil equação a ser resolvida: conciliar o combate à pobreza à autonomia das mulheres. O Programa Bolsa Família elege a mulher como principal beneficiária, suscitando controvérsias: enquanto alguns sinalizam uma perda de autonomia da mulher em face do mercado de trabalho, outros reconhecem o fortalecimento de seu papel na família.

Dada a sua amplitude temporal, abrangência social e escala espacial, esse Programa constitui-se como uma política pública que propõe a mitigação de uma situação grave e específica, a fome e a miséria. Entretanto, ele confere visibilidade e alavanca rumo à transformação de outra situação, a condição desigual da mulher na sociedade. Certamente, essa última questão articula-se com a anterior, abrindo e ampliando seus objetivos iniciais, e comprovando o potencial emancipador das políticas

3 Golay, Christophe; ÖZDEN, Melik. Le droit à l'alimentation. Un droit humain fondamental stipulé par l'ONU et reconnu par des traités régionaux et de nombreuses constitutions nationales. Une collection du Programme Droit Humains du Centre Europe - Tiers Monde (CETIM) . Disponível em : < http:/ / www.eoi.at/d/EOI\%20 -\%20Jahresberichte/Monaco/bro1-alim-A4-fr.pdf>. Acesso em: 06 out. 2016. p. 3.

4 Entende-se a condição feminina como o status ou situação da mulher na ordem das relações e representações sociais relativas a determinado contexto social ou cultural. Cada sociedade concretiza em seus termos esta condição. 
públicas que buscam a efetivação dos direitos humanos. É nesses termos que se indaga por um empoderamento ${ }^{5}$ feminino às avessas.

Utilizando-se do método de pesquisa dedutivo, o trabalho parte do tema do direito humano e fundamental à alimentação adequada para desaguar na condição feminina. Para percorrer esse caminho, o trabalho vale-se de dados empíricos do IBGE, relativos ao censo 2010, e do Ministério do Desenvolvimento Social sobre o Programa Bolsa Família que apontam o alto percentual de responsabilidade feminina em famílias monoparentais. Ao seguir o procedimento de pesquisa bibliográfico, elege como marcos teóricos a concepção intercultural de direitos humanos de Joaquín Herrera Flores, as críticas de Bila Sorj e Andréa Gama acerca das políticas públicas brasileiras em favor da família, e as categorias de reconhecimento, redistribuição e representação, problematizadas por Nancy Fraser. Conclui-se pelo fortalecimento do papel da mulher, ao ser eleita como beneficiária principal do Programa Bolsa Família.

O plano de trabalho divide-se em três partes: (i) a primeira delineia a afirmação do direito humano à alimentação adequada no embate entre universalismo e relativismo; (ii) a segunda atem-se à recepção do direito humano e fundamental à alimentação adequada e sua articulação em políticas públicas de segurança alimentar e nutricional voltadas à família; e (iii) a terceira cumpre o desafio de discutir a condição feminina no Programa Bolsa Família.

\section{ENTRE UNIVERSALISMO E RELATIVISMO: A AFIRMAÇÃO DO DIREITO HUMANO À ALIMENTAÇÃO ADEQUADA}

Os direitos humanos são produtos da época moderna, mas estão no seu apogeu ${ }^{6}$. Trata-se de um paradoxo

5 Trata-se da “...autodeterminação de indivíduos e comunidades, objetivando uma participação simbólica e real na busca da democracia e equidade, em que o profissional assume um papel importante na mediação de processos propulsores do empoderamento.” KLEBA, Maria Elisabeth; WENDAUSEN, Agueda. Empoderamento: processo de fortalecimento dos sujeitos nos espaços de participação social e democratização política. Saúde e sociedade, São Paulo, v. 18, n. 4, p. 733-743, 2009. Disponível em: <http://www.scielo.br/pdf/ sausoc/v18n4/16.pdf>. Acesso em: 29 out. 2016. p. 742.

6 VILLEY, Michel. $O$ direito e os direitos bumanos. São Paulo: M. Fontes, 2007. p. 2. do qual Michel Villey vale-se para descrever a trajetória desses direitos, afirmando que irromperam, logo após a Revolução de 1789, na Europa moderna ${ }^{7}$. Se na Declaração dos Direitos do Homem e do Cidadão os direitos humanos representaram, em uma perspectiva contratualista, a luta contra o absolutismo político ${ }^{8}$, no século XX, surgiram, novamente, como recurso, dessa vez, na luta contra o totalitarismo?.

A Primeira Grande Guerra legou coletividades de pessoas destituídas de seus territórios, que deveriam ser eliminadas ou assimiladas, pois provocavam uma tensão entre o Estado e a nação ${ }^{10}$. Os regimes totalitários, por sua vez, promoveram a desnacionalização em massa, ensejando os apátridas e sinalizando uma ruptura dos direitos humanos ${ }^{11}$. Por ocasião da Segunda Grande Guerra, o Estado mostra-se como principal violador desses direitos, resultando em uma reconstrução do referencial ético no plano internacional, por meio da Declaração Universal de 1948. Afirma-se a ideia segundo a qual a proteção desses direitos não pode se reservar ao domínio do Estado, passando-se da jurisdição doméstica à jurisdição internaciona ${ }^{12}$. Eis, segundo Flávia Piovesan, a concepção contemporânea de direitos humanos, caracterizada pela universalidade e indivisibilidade desses direitos ${ }^{13}$. A primeira garante que ser pessoa é requisito suficiente para sua titularidade, e a segunda estabelece que a garantia dos direitos civis e políticos é condição para a observação dos direitos sociais, econômicos e culturais ${ }^{14}$.

7 VILLEY, Michel. O direito e os direitos humanos. São Paulo: M. Fontes, 2007. p. 9-10.

8 VILLEY, Michel. O direito e os direitos humanos. São Paulo: M. Fontes, 2007. p. 4.

9 VILLEY, Michel. O direito e os direitos humanos. São Paulo: M. Fontes, 2007. p. 4.

10 LAFER, Celso. A reconstrução dos direitos humanos. Um diálogo com o pensamento de Hannah Arendt. São Paulo: Companhia das Letras, 2009. p. 142.

11 LAFER, Celso. A reconstrução dos direitos humanos. Um diálogo com o pensamento de Hannah Arendt. São Paulo: Companhia das Letras, 2009. p. 144.

12 PIOVESAN, Flávia. A universalidade e a indivisibilidade dos direitos humanos: desafios e perspectivas. In: BALDI, César Augusto (org.). Direitos humanos na sociedade cosmopolita. Rio de Janeiro: Renovar, 2004. p. 48.

13 PIOVESAN, Flávia. A universalidade e a indivisibilidade dos direitos humanos: desafios e perspectivas. In: BALDI, César Augusto (org.). Direitos humanos na sociedade cosmopolita. Rio de Janeiro: Renovar, 2004. p. 45-71, p. 57.

14 PIOVESAN, Flávia. A universalidade e a indivisibilidade dos direitos humanos: desafios e perspectivas. In: BALDI, César Augusto (org.). Direitos humanos na sociedade cosmopolita. Rio de Janeiro: Renovar, 2004. p. 57. 
Esse processo apoia-se na restrição da soberania estatal e na concepção universal desses direitos. Esboça-se, então, um sistema normativo internacional de proteção aos direitos humanos, representado pela criação da Organização das Nações Unidas em 1945 e pela Declaração Universal dos Direitos do Homem de $1948^{15}$. A Declaração combina os direitos civis e políticos, denominados de primeira geração, com os direitos sociais, econômicos e culturais de segunda geração, rompendo com a tese geracional dos direitos humanos ${ }^{16}$. Também traz consigo uma universalidade de corte axiológico ${ }^{17}$, expressa pelo princípio da dignidade da pessoa humana, que é recepcionada tardiamente pelos ordenamentos jurídicos contemporâneos, como é o caso do artigo $1^{\circ}$, III, da Constituição da República de 1988.

No plano internacional, o artigo XXVI da Declaração Universal de Direitos Humanos de 1948 afirma o direito à alimentação, dentre outros, tem caráter obrigatório. A vantagem dessa afirmação está, justamente, em seu caráter universalista, pois, hoje, a Declaração é aceita por todos os Estados ${ }^{18}$. Rende-se, então, ao direito à alimentação a característica de um direito universal $^{19}$, passível de proteção em um sistema normativo internacional.

No contexto da garantia dos direitos humanos universais, o direito à alimentação adequada foi, expressamente, acolhido pelo Pacto Internacional de Direitos Econômicos, Sociais e Culturais de 1966, em seu artigo 11, como obrigatório para todos os Estados que o aceitaram ou o ratificaram, dentre os quais o Brasil em

15 FACHIN, Melina Girardi. Fundamentos dos direitos humanos: Teoria e práxis na cultura da tolerância. Rio de Janeiro: Renovar, 2009. p. 59-61.

16 Cf. FLORES, Joaquín Herrera. A (re) invenção dos direitos bumanos. Florianópolis: Fundação Boiteux e IDHID, 2009. p. 75-76.

17 FACHIN, Melina Girardi. Fundamentos dos direitos humanos: Teoria e práxis na cultura da tolerância. Rio de Janeiro: Renovar, 2009. p. 69.

18 Golay, Christophe; ÖZDEN, Melik. Le droit à l'alimentation. Un droit humain fondamental stipulé par l'ONU et reconnu par des traités régionaux et de nombreuses constitutions nationales. Une collection du Programme Droit Humains du Centre Europe - Tiers Monde (CETIM) . Disponível em : < http://www.eoi.at/d/EOI\%20 -\%20Jahresberichte/Monaco/bro1-alim-A4-fr.pdf>. Acesso em: 06 out. 2016. p. 10.

19 Golay, Christophe; ÖZDEN, Melik. Le droit à l'alimentation. Un droit humain fondamental stipulé par l'ONU et reconnu par des traités régionaux et de nombreuses constitutions nationales. Une collection du Programme Droit Humains du Centre Europe - Tiers Monde (CETIM) . Disponível em : < http://www.eoi.at/d/EOI\%20 -\%20Jahresberichte/Monaco/bro1-alim-A4-fr.pdf>. Acesso em: 06 out. 2016. p. 8.
1992. Segundo Islândia Costa Bezerra e Kátya Regina Isaguirre, isso "representa um avanço imensurável", sendo possível afirmar que "vislumbra o conhecimento e o reconhecimento, por parte de toda a sociedade, de que o acesso a uma alimentação adequada corresponde, por si só, ao direito de existir e coexistir, vinculado diretamente ao valor da dignidade humana" ${ }^{20}$.

No entanto, o universalismo é passível de críticas, ao se indagar se as normas de direitos humanos têm um sentido tão somente universal ou se são culturalmente relativas ${ }^{21}$. Para os relativistas ${ }^{22}$, cada cultura tem um discurso próprio acerca desses direitos, não havendo lugar para uma moral universal, e sendo imprescindível respeitar as diferenças culturais ${ }^{23}$. Por conseguinte, a internacionalização dos direitos humanos está hoje pulverizada nos sistemas internacional e regional de proteção desses direitos ${ }^{24}$.

O direito humano à alimentação adequada é acolhido, então, no plano regional. O Protocolo de San Salvador de 1988, que completa a Convenção Americana dos Direitos Humanos de 1969, reconhece expressamente em seu artigo 12 o direito à alimentação adequada $a^{25}$, tendo sido ratificado pelo Brasil. Já a Carta Africana dos

20 BEZERRA, Islândia Costa; ISAGUIRRE, Kátya Regina. Direito humano à alimentação adequada (DHAA): a discussão da "geografia da fome" à sua proteção jurídica no Brasil, Revista Pensar, Fortaleza, v. 18, n. 3, p. 675-692, set./dez. 2014. p. 677.

21 PIOVESAN, Flávia. A universalidade e a indivisibilidade dos direitos humanos: desafios e perspectivas. In: BALDI, César Augusto (org.). Direitos humanos na sociedade cosmopolita. Rio de Janeiro: Renovar, 2004. p. 45-71, p. 58.

22 Sobre as formas de relativismo consultar: PIOVESAN, Flávia. A universalidade e a indivisibilidade dos direitos humanos: desafios e perspectivas. In: BALDI, César Augusto (org.). Direitos bumanos na sociedade cosmopolita. Rio de Janeiro: Renovar, 2004. p. 45-71, p. 61.

23 PIOVESAN, Flávia. A universalidade e a indivisibilidade dos direitos humanos: desafios e perspectivas. In: BALDI, César Augusto (org.). Direitos humanos na sociedade cosmopolita. Rio de Janeiro: Renovar, 2004. p. 45-71, p. 60.

24 FACHIN, Melina Girardi. Fundamentos dos direitos humanos: Teoria e práxis na cultura da tolerância. Rio de Janeiro: Renovar, 2009. p. 69.

25 "Toda pessoa tem direito a uma alimentação adequada que lhe assegure a possibilidade de atingir seu pleno desenvolvimento físico e seu pleno desenvolvimento afetivo e intelectual." Tradução livre de: "Toute personne a droit à une alimentation adéquate qui lui assure la possibilité d'atteindre son plein développement physique et son plein épanouissement affectif et intellectuel. » (Apud Golay, Christophe; ÖZDEN, Melik. Le droit à l'alimentation. Un droit humain fondamental stipulé par l'ONU et reconnu par des traités régionaux et de nombreuses constitutions nationales. Une collection du Programme Droit Humains du Centre Europe - Tiers Monde (CETIM). Disponível em: <http://www.eoi. at/d/EOI\%20-\%20Jahresberichte/Monaco/bro1-alim-A4-fr.pdf >. Acesso em: 06 out. 2016. p. 12. 
Direitos Humanos e dos Povos não reconhece, explicitamente, o direito à alimentação, mas prevê um conjunto de direitos, no artigo 16, para seu reconhecimento. Em seu artigo 60, prevê que os Estados africanos devem realizar o direito à alimentação, previsto no plano internacional, aceitando o Pacto Internacional de Direitos Econômicos, Sociais e Culturais. A Carta Africana dos Direitos e bem-estar da Criança, expressamente, assegura, em seu artigo 14, o fornecimento de alimentação adequada e água potável ${ }^{26}$. A Carta Social Europeia de 1961 contempla uma proteção tão somente parcial do direito à alimentação, uma vez que o considera, suficientemente protegido, por meio da previsão do direito ao trabalho, à assistência e à seguridade social ${ }^{27}$.

As diferenças culturais, proclamadas pelos relativistas, mostram-se visíveis quando está em jogo o direito humano à alimentação: indivíduos e grupos mais vulneráveis da sociedade, constantemente discriminados, como as mulheres, crianças, camponeses sem terra, povos indígenas, pescadores, desempregados são os que estão mais sujeitos à fome. Para Christophe Golay e Melik Özden, a solução está em considerar o direito à alimentação como um direito que pertence a todos sem discriminação alguma ${ }^{28}$. Nessa perspectiva, a Convenção sobre Eliminação de todas as Formas de Discriminação das Mulheres estabelece em seus artigos 12 e 14, que o direito à alimentação é reconhecido a todas as mulheres; a Convenção dos Direitos da Criança, nos artigos 24 e 27, garante o direito à alimentação à infância; a Convenção do Estatuto dos Refugiados, nos artigos 20 e 23, garante esse direito aos refugiados; e a Conven-

26 Golay, Christophe; ÖZDEN, Melik. Le droit à l'alimentation. Un droit humain fondamental stipulé par l'ONU et reconnu par des traités régionaux et de nombreuses constitutions nationales. Une collection du Programme Droit Humains du Centre Europe - Tiers Monde (CETIM) . Disponível em : < http://www.eoi.at/d/EOI\%20 -\%20Jahresberichte/Monaco/bro1-alim-A4-fr.pdf>. Acesso em: 06 out. 2016. p. 13.

27 Golay, Christophe; ÖZDEN, Melik. Le droit à l'alimentation. Un droit humain fondamental stipulé par l'ONU et reconnu par des traités régionaux et de nombreuses constitutions nationales. Une collection du Programme Droit Humains du Centre Europe - Tiers Monde (CETIM) . Disponível em : < http://www.eoi.at/d/EOI\%20 -\%20Jahresberichte/Monaco/bro1-alim-A4-fr.pdf>. Acesso em: 06 out. 2016. p. 14.

28 Golay, Christophe; ÖZDEN, Melik. Le droit à l'alimentation. Un droit humain fondamental stipulé par l'ONU et reconnu par des traités régionaux et de nombreuses constitutions nationales. Une collection du Programme Droit Humains du Centre Europe - Tiers Monde (CETIM) . Disponível em : < http://www.eoi.at/d/EOI\%20 -\%20Jahresberichte/Monaco/bro1-alim-A4-fr.pdf>. Acesso em: 06 out. 2016. p. 8. ção dos Povos Indígenas e Tribais, nos artigos 14 a 19, garante a estes povos o direito em questão ${ }^{29}$.

A complexidade dos direitos humanos na sociedade atual não pode ser reduzida à mera contraposição entre universalismo e relativismo. Trata-se de refletir acerca do homem ou da cultura como fundamento desses direitos. Para tanto, o primeiro passo é partir da convicção que os problemas culturais que desafiam os direitos humanos são também problemas políticos e econômi$\cos ^{30}$. Nessa perspectiva, Joaquín Herrera Flores considera o universalismo como uma concepção abstrata de direitos humanos, ancorada em uma racionalidade formal, que ignora a diversidade e diferenças de poder entre identidades sociais diversas. Igualmente, rechaça a concepção relativista como uma visão localista, que ao universalizar seus particularismos, justifica a violação dos direitos humanos ${ }^{31}$. Por isso, propõe a superação dos extremos, por meio de um "universalismo de confluência", segundo o qual o universal não é o ponto de partida, mas o ponto de chegada. Ancorado em uma prática intercultural, o autor afirma que os direitos humanos não são meras declarações textuais ou produtos de uma única cultura, mas processos dinâmicos, que permitem a abertura e consolidação de espaços de luta pela dignidade humana ${ }^{32}$.

Com amparo nos ensinamentos acima, o direito humano à alimentação adequada pode ser compreendido como um produto cultural, "como algo que surge em uma determinada realidade, fruto de um conjunto de relações sociais" ${ }^{33}$. Essa ideia reflete-se no Comentário Geral no 12 da ONU, delineando os elementos essenciais do direito humano à alimentação adequada: dispo-

29 Golay, Christophe; ÖZDEN, Melik. Le droit à l'alimentation. Un droit humain fondamental stipulé par l'ONU et reconnu par des traités régionaux et de nombreuses constitutions nationales. Une collection du Programme Droit Humains du Centre Europe - Tiers Monde (CETIM) . Disponível em : < http://www.eoi.at/d/EOI\%20 -\%20Jahresberichte/Monaco/bro1-alim-A4-fr.pdf > . Acesso em: 06 out. 2016. p. 11.

30 FACHIN, Melina Girardi. Fundamentos dos direitos humanos: Teoria e práxis na cultura da tolerância. Rio de Janeiro: Renovar, 2009. p. 231-234.

31 FACHIN, Melina Girardi. Fundamentos dos direitos bumanos: Teoria e práxis na cultura da tolerância. Rio de Janeiro: Renovar, 2009. p. $235-242$.

32 FLORES, Joaquín Herrera. A (re) invenção dos direitos humanos. Florianópolis: Fundação Boiteux e IDHID, 2009. p. 68.

33 BEZERRA, Islândia Costa; ISAGUIRRE, Kátya Regina. Direito humano à alimentação adequada (DHAA): a discussão da "geografia da fome" à sua proteção jurídica no Brasil, Revista Pensar, Fortaleza, v. 18, n. 3, p. 675-692, set./dez. 2014. p. 682. 
nibilidade e acesso. Em relação ao primeiro, a alimentação além de ser culturalmente aceitável e passível de satisfazer, em termos quantitativos e qualitativos, as necessidades alimentares do indivíduo, deve ser disponível a cada pessoa, sendo obtida, diretamente, dos recursos naturais ou de um sistema de distribuição adequada. Em relação ao segundo, toda a pessoa deve ter acesso fisicamente e economicamente à alimentação. $\mathrm{O}$ acesso físico se traduz em uma alimentação suficiente e adequada para toda a pessoa, seja ela vulnerável ou não. E o acesso econômico significa que as despesas com uma alimentação suficiente e adequada não podem colocar em risco a fruição de outros direitos humanos ${ }^{34}$.

A perspectiva dos direitos humanos como espaços de luta pela dignidade enseja a discussão sobre o papel dos Estados na concretização desses direitos. Quanto a esse aspecto, Christophe Golay e Melik Özden proclamam que não se trata de uma opção política, mas da obrigação de respeitar, proteger e tornar efetivo o direito humano à alimentação adequada. Em relação ao primeiro, exemplificam os autores que o Estado não pode destituir os povos indígenas e outras minorias de suas terras ou empreender políticas econômicas que resultem no desemprego massivo ou perda do poder aquisitivo da população. Em relação ao segundo, afirmam que o Estado deve impedir que terceiros, como empresas nacionais e transnacionais, deteriorem recursos naturais que possibilitam a alimentação de indivíduos e coletividades. E, finalmente, facilitar e realizar o direito à alimentação, por meio de políticas públicas ou do fornecimento direto àqueles que não têm nenhuma chance de acesso $^{35}$.

Para tanto, o Pacto Internacional dos Direitos Econômicos, Sociais e Culturais impõe aos Estados signatários a obrigação de progressividade na implantação desses direitos e proíbe “...o retrocesso ou a redução

34 Golay, Christophe; ÖZDEN, Melik. Le droit à l'alimentation. Un droit humain fondamental stipulé par l'ONU et reconnu par des traités régionaux et de nombreuses constitutions nationales. Une collection du Programme Droit Humains du Centre Europe - Tiers Monde (CETIM) . Disponível em : < http://www.eoi.at/d/EOI\%20 -\%20Jahresberichte/Monaco/bro1-alim-A4-fr.pdf>. Acesso em: 06 out. 2016. p. 7.

35 Golay, Christophe; ÖZDEN, Melik. Le droit à l'alimentation. Un droit humain fondamental stipulé par l'ONU et reconnu par des traités régionaux et de nombreuses constitutions nationales. Une collection du Programme Droit Humains du Centre Europe - Tiers Monde (CETIM) . Disponível em : < http://www.eoi.at/d/EOI\%20 -\%20Jahresberichte/Monaco/bro1-alim-A4-fr.pdf>. Acesso em: 06 out. 2016. p. 15-16. de políticas públicas voltadas à garantia de tais direitos, cabendo ao Estado o ônus da prova" ${ }^{" 36}$. Cabe, ainda, aos Estados partes assegurar o "núcleo essencial mínimo", que se traduz no "dever de observância do mínimo essencial concernente aos direitos econômicos, sociais e culturais [que] tem como fonte o princípio da dignidade humana [...] demandando absoluta urgência e prioridade" ${ }^{37}$. Indaga-se, então, como o Brasil recepcionou o direito humano à alimentação adequada, cumprindo a obrigação de implantação deste direito, por meio de políticas públicas em favor da segurança alimentar e nutricional.

\section{As POLÍTICAS PÚBLICAS EM FAVOR DO DIREITO HUMANO E FUNDAMETAL À ALIMENTAÇÃO ADEQUADA}

O Brasil coloca-se, dentre os aproximadamente vinte países $^{38}$, que recepcionaram o direito humano à alimentação adequada expressamente em seu direito interno. Não obstante, já fosse possível deduzi-lo de outros direitos fundamentais ${ }^{39}$, ingressou tardiamente no rol de direitos fundamentais sociais do artigo $6^{\circ}$ da Constituição da República, por meio da Emenda Constitucional $n^{\circ} 64 / 2010^{40}$.

A recepção do direito à alimentação adequada na Constituição da República evidencia sua passagem de direito humano a direito fundamental. Trata-se de uma distinção tradicionalmente realizada pela doutrina, segundo a qual a denominação "direitos humanos" é reservada ao direito internacional, enquanto a denomi-

36 PIOVESAN, Flávia. Direitos bumanos e o direito constitucional internacional. 12. ed. São Paulo: Saraiva, 2011. p. 235.

37 PIOVESAN, Flávia. Direitos humanos e o direito constitucional internacional. 12. ed. São Paulo: Saraiva, 2011. p. 235-236.

38 NIVARD, Carole. Le droit à l'alimentation. La Revue des Droits de l'Homme, jun. 2012. Disponível em: <http://revdh.files.wordpress.com/2012/06/le-droit-c3a0-lalimentation.pdf $>$. Acesso em: 06 out. 2016. p. 1.

39 Cf. Marcela Müller, ao arrolar os seguintes artigos da Constituição da República: art. $1^{\circ}$, III; art. $3^{\circ}$, III; art. $4^{\circ}$, II; art. $6^{\circ}$; art. $7^{\circ}$, IV; art. 23, VIII e X; art. 208, VII; art.225; art. 227. MÜLLER, Marcela. O direito social fundamental à alimentação adequada e sua proteção no contexto das organizações internacionais. 2014. 143 f. Dissertação (Mestrado em Direito) - Programa de Pós-Graduação em Direito, Universidade de Itaúna, Itaúna, 2014. p. 45.

40 Cf. MÜLLER, Marcela. O direito social fundamental à alimentação adequada e sua proteção no contexto das organizações internacionais. 2014. 143 f. Dissertação (Mestrado em Direito) - Programa de Pós-Graduação em Direito, Universidade de Itaúna, Itaúna, 2014. p. 45-46. 
nação "direitos fundamentais" é característica do direito interno. Entretanto, questiona-se uma possível fragmentação desses direitos operada por esta distinção ${ }^{41}$. Para António-Enrique Perez Luño, referida distinção é inadmissível, pois a diferença reside no grau de concreção positiva:

Los derechos humanos suelen venir entendidos como un conjunto de facultades e instituciones que, en cada momento histórico, concretan las exigencias de la dignidad, la liberdad y la igualdad humanas, las cuales deben ser reconocidas positivamente por los ordenamientos jurídicos a nivel nacional e internacional. En tanto que con la noción de los derechos fundamentales se tiende a ludir a aquellos derechos humanos garantizados por el ordenamiento jurídico positivo, en la mayor parte de los casos en su normativa constitucional, y que suelen gozar de una tutela reforzada ${ }^{42}$.

Com amparo nesse autor, Melina Girard Fachin proclama uma aproximação entre direitos humanos e fundamentais, em face de sua finalidade comum: a proteção efetiva da pessoa humana. É possível afirmar que ambos convergem para a concretização do princípio da dignidade da pessoa humana, sendo preferível denominar o direito à alimentação adequada de direito humano e fundamental ${ }^{43},{ }^{44}$.

O direito humano e fundamental à alimentação adequada está relacionado à fome e à desnutrição. Entretanto, a fome não se reduz apenas aos aspectos biológicos e econômicos. Por outras palavras, não é possível considerá-la tão somente como uma "sensação fisiológica ligada à vontade de comer”, ou dimensioná-la a partir da disponibilidade de alimentos no mercado ou domicílios, tomando por base os gastos familiares ou características do consumo alimentar e, sequer por meio de indicadores de estado nutricional diretos ou indiretos da população ${ }^{45}$. Antes, assevera Flávio Luiz Schieck Va-

41 Cf. FACHIN, Melina Girardi. Todos os nomes e um só sentido: a aproximação dos direitos humanos aos direitos fundamentais tendo em vista sua efetivação prática. Revista Brasileira de Direito Internacional, Curitiba, v. 3, n. 3, jan./jun. 2006. p. 55.

42 LUÑO, António E. Pérez. Los derechos fundamentales. 10. ed. Madrid: Editorial Tecnos, 2011. p. 42. (Temas clave de la Constituicion española).

43 FACHIN, Melina Girardi. Todos os nomes e um só sentido: a aproximação dos direitos humanos aos direitos fundamentais tendo em vista sua efetivação prática. Revista Brasileira de Direito Internacional, Curitiba, v. 3, n. 3, jan./jun. 2006. p. 68.

44 Com base nessa doutrina, que reconhece uma aproximação entre as concepções de direitos humanos e direitos fundamentais, doravante o direito à alimentação adequada será denominado “direito humano e fundamental".

45 VALENTE, Flávio Luiz Schieck. Fome, desnutrição e cidada- lente que a fome tem facetas subjetivas e qualquer

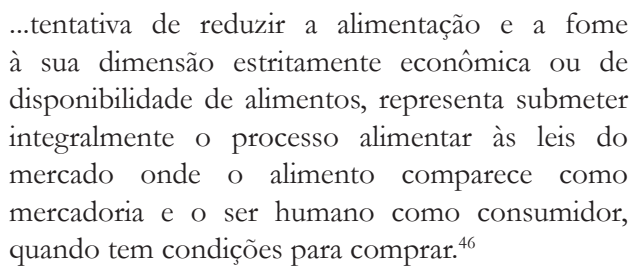

A desnutrição, por sua vez, engloba tanto carências nutricionais como uma ingestão excessiva ou desbalanceada de nutrientes, de tal modo que a obesidade e o consumo inadequado de alimentos mostram-se como problemas de saúde pública. Desse modo, a quantidade e a qualidade do alimento que é oferecido à população, sua produção e comercialização podem se caracterizar como obstáculos à realização do direito humano e fundamental à alimentação adequada. Nos países latino-americanos, isso requer uma alteração da perspectiva da economia agrícola, de mera lógica mercantil à afirmação daquele direito ${ }^{47}$.

Delineia-se um quadro de insegurança alimentar e nutricional que leva à necessidade de elaboração de uma Política Nacional de Segurança Alimentar e Nutricional, editando-se a Lei $n^{\circ} 11.346 / 2006$, denominada de Lei Orgânica de Segurança Alimentar e Nutricional (LOSAN). Sob o princípio da dignidade da pessoa humana $\left(\operatorname{artigo~} 2^{\circ}\right.$ ), essa lei conceitua a segurança alimentar e nutricional como o direito de todos ao acesso regular, permanente, de qualidade, em quantidade suficiente, sem comprometer outros bens essenciais, baseado em práticas alimentares saudáveis, que respeitem a diversidade cultural e sejam ambiental, cultural, econômica e socialmente sustentáveis (artigo $3^{\circ}$ ). Desse modo, o direito humano e fundamental à alimentação adequada articula-se com outros direitos fundamentais sociais, sendo destes, indissociável.

$\mathrm{O}$ artigo $7^{\circ}$ da LOSAN cria o Sistema Nacional de Segurança Alimentar e Nutricional (SISAN), integrado por um conjunto de órgãos dos entes federados e instituições privadas sem fins lucrativos, que tem por objetivo formular e implementar políticas públicas e planos

nia: inclusão social e direitos humanos. Saúde e sociedade, São Paulo, v. 12, n. 1, p. 51-60, jan./jun., 2003. p. 57.

46 VALENTE, Flávio Luiz Schieck. Fome, desnutrição e cidadania: inclusão social e direitos humanos. Saúde e sociedade, São Paulo, v. 12, n. 1, p. 51-60, jan./jun., 2003. p. 57.

47 BEZERRA, Islândia Costa; ISAGUIRRE, Kátya Regina. Direito humano à alimentação adequada (DHAA): a discussão da "geografia da fome" à sua proteção jurídica no Brasil, Revista Pensar, Fortaleza, v. 18, n. 3, p. 675-692, set./dez. 2014. p. 689. 
de segurança alimentar e nutricional, bem como sua promoção, acompanhamento, monitoramento e avaliação (artigo 10). A implementação de políticas públicas para realização do direito humano e fundamental à alimentação adequada, deve respeitar a multiplicidade de características culturais do País, (artigo 4, VI, LOSAN), de tal modo que uma parcela de relativismo cultural tece a segurança alimentar e nutricional.

As políticas públicas em favor do direito humano e fundamental à alimentação adequada inserem-se no sistema de reordenação traçado pela Constituição da República de 1988. Para tanto, passou a considerar os direitos sociais como fundamentais, estabelecendo o compromisso do Estado com o sistema de proteção social, o que acentuou o seu grau de comprometido financeiro e o papel complementar do setor privado para o cumprimento desta tarefa. Estabeleceu a concepção de seguridade social como a forma mais abrangente de proteção e orientou-se pela descentralização e participação social nestas atividades ${ }^{48}$. Entretanto, se por um lado, a Constituição estabeleceu novos princípios, por outro, o Estado engajou-se no projeto neoliberal, que nas últimas décadas resultaram no desmantelamento do sistema de proteção social. Por conseguinte, a "nova política econômica" contrapõe-se à "nova política de proteção social", o que levou o governo brasileiro a optar pela diminuição de financiamento de programas e políticas sociais ${ }^{49}$.

Segundo Flávio Luiz Schieck Valente, o direito humano e fundamental à alimentação adequada deve ser considerado como inseparável do direito à nutrição, dependendo não apenas da disponibilidade de alimentos, mas do respeito às práticas e hábitos alimentares, do estado de saúde das pessoas, da prestação de cuidados especiais aos grupos mais vulneráveis, como crianças, idosos, gestantes, pessoas com deficiência, e de nutrir a si próprio e à sua família com dignidade ${ }^{50}$. Desse modo, é imprescindível que as políticas públicas de segurança alimentar e nutricional atentem para a condição feminina, em razão do papel fundamental desempenhado pela

48 SORJ, Bila.; GAMA, Andréa. Family Policies in Brazil. ROBILA, Mihaela (Coord.). Handbook of family policies across the globe. New York City: Springer, 2014. p. 459-471, p. 459.

49 SORJ, Bila.; GAMA, Andréa. Family Policies in Brazil. ROBILA, Mihaela (Coord.). Handbook of family policies across the globe. New York City: Springer, 2014. p. 459-471, p. 467-468.

50 VALENTE, Flávio Luiz Schieck. Fome, desnutrição e cidadania: inclusão social e direitos humanos. Saúde e sociedade, São Paulo, v. 12, n. 1, p. 51-60, jan./jun., 2003. p. 54. mulher no ciclo da vida e na alimentação da família ${ }^{51}$. Com efeito, as políticas públicas de segurança alimentar e nutricional traduzem-se em políticas públicas em favor da família.

As transformações da família, que se delinearam nas últimas décadas, propõem dois desafios às políticas públicas conduzidas pelo Estado brasileiro nesta seara: (i) dissipar sua fragmentação e (ii) promover a "liberdade de ser na família" 52 .

O primeiro decorre do fenômeno de descodificação do Direito Privado, que legou leis especiais para regular predominante o Direito de Família, como a Lei 8.069/1990 (Estatuto da Criança e do Adolescente) e a Lei 10.741/2003 (Estatuto do Idoso), constituindo microssistemas que tutelam a pessoa sob uma perspectiva interdisciplinar. Por conseguinte, as políticas públicas passaram a ser dirigidas à infância e adolescência, aos idosos, às mulheres, como reflexo dessa pluralidade de estatutos jurídicos. Delineia-se, então, uma política social fragmentada, posto que limitada pela ausência de políticas públicas mais abrangentes. Eis que, por vezes, uma família pobre recebe uma renda mensal, que lhe permite aumentar o consumo, mas mora em local sem qualquer infraestrutura ${ }^{53}$. Em última instância, realiza-se uma política pública em favor do mercado, capaz de aumentar o poder de consumo, mas incapaz de dissipar a desigualdade social entre as famílias ${ }^{54}$.

O segundo decorre da prioridade conferida às mulheres como beneficiárias de programas de transferência de renda, pois elas preferem investir os recursos da família no bem-estar de seus filhos, enquanto os homens tendem a utilizá-los em seu próprio bem-estar.

51 Cf. FRANÇA, Alexandra Beurlen de. O direito bumano à alimentação adequada no Brasil. 2004. 260 f. Dissertação (Mestrado em Direito) - Programa de Pós-Graduação em Direito, Universidade Federal de Pernambuco, Recife, 2004. p. 96.

52 Cf. VILLELA, João Baptista. Liberdade e família. Monografia (TCC) - Faculdade de Direito da UFMG, Belo Horizonte 1980. p. 16.

53 SORJ, Bila.; GAMA, Andréa. Family Policies in Brazil. ROBILA, Mihaela (Coord.). Handbook of family policies across the globe. New York City: Springer, 2014. p. 463.

54 Para Bila Sorj e Andréa Gama, o sistema dualista de políticas públicas no Brasil faz com que estas sejam dirigidas às famílias extremamente pobres, restando às famílias assalariadas e de classe média o estímulo de obtenção de segurança social no mercado, o que reproduz a desigualdade social entre as famílias. SORJ, Bila.; GAMA, Andréa. Family Policies in Brazil. ROBILA, Mihaela (Coord.). Handbook of family policies across the globe. New York City: Springer, 2014. p. 460 
Tais fatos apontam para políticas públicas dirigidas às mães e às crianças, questionando-se sua suficiência para promoção da "liberdade de ser na família" ${ }^{55}$. Trata-se de conciliar o combate à pobreza com a promoção da autonomia das mulheres, substituindo a campanha contra a pobreza de viés maternalista forte, por políticas que melhorem o nível e a qualidade da participação das mães no mercado de trabalho ${ }^{56}$.

Dentre as políticas públicas em favor de famílias em situação de risco, elaboradas pelo Estado brasileiro nos últimos anos, estão os programas de transferência de renda como o Programa Bolsa Família, ao qual se condensa o segundo desafio. Ele tem sido objeto de intensa discussão por priorizar a mulher. Enquanto alguns opinam que ele fomenta o papel da mulher como mãe, privilegiando a família, outros afirmam que ele desencoraja a participação da mulher do mercado de trabalho, enfraquecendo sua autonomia ${ }^{57}$. É a discussão que adiante se enfrenta.

\section{A Condição feminina e o programa Bolsa Família}

Os últimos anos apontam um novo perfil das famílias brasileiras. Em face do princípio da pluralidade familiar, a Constituição da República acolhe as famílias monoparentais, formadas por apenas um dos cônjuges e seus filhos, no artigo 226. Dados do IBGE revelam que $37,3 \%$ das famílias brasileiras têm como responsável a mulher ${ }^{58}$, o que se deve ao alto índice de divórcios e separações e ao crescimento da gravidez na adolescência. E nas famílias monoparentais, $87,4 \%$ das mulheres são apontadas como responsáveis pelo grupo ${ }^{59}$.

55 Cf. VILLELA, João Baptista. Liberdade e família. Monografia (TCC) - Faculdade de Direito da UFMG, Belo Horizonte 1980. p. 16.

56 SORJ, Bila.; GAMA, Andréa. Family Policies in Brazil. ROBILA, Mihaela (Coord.). Handbook of family policies across the globe. New York City: Springer, 2014. p. 469.

57 SORJ, Bila.; GAMA, Andréa. Family Policies in Brazil. ROBILA, Mihaela (Coord.). Handbook of family policies across the globe. New York City: Springer, 2014. p. 467.

58 IBGE. Estatísticas de gênero. Uma análise dos resultados do censo demográfico 2010. Disponível em: <http://biblioteca.ibge. gov.br/visualizacao/livros/liv88941.pdf>. Acesso em: 25 out. 2016, p. 65.

59 IBGE. Estatísticas de gênero. Uma análise dos resultados do censo demográfico 2010. Disponível em: <http://biblioteca.ibge.gov.br/ visualizacao/livros/liv88941.pdf>. Acesso em: 25 out. 2016. p. 65.
Tais fatos representam um desafio à concretização do direito humano e fundamental à alimentação adequada: a desigualdade de gêneros.

No plano internacional, o Pacto Internacional sobre Direitos Econômicos, Sociais e Culturais buscou conter o ciclo de discriminação feminina, caracterizada, dentre outros aspectos, por um fraco poder de negociação doméstico e a distribuição desproporcional de tarefas e responsabilidades familiares. Eis que estabelece em seus artigos $2^{\circ}$ e $3^{\circ}$, a igualdade entre homens e mulheres no que se refere aos direitos econômicos, sociais e culturais. A Convenção sobre Eliminação de todas as Formas de Discriminação, no artigo 12, impõe aos Estados partes a obrigação de prover uma nutrição adequada durante a gravidez e o aleitamento materno. Igualmente, impõe medidas apropriadas para eliminar a discriminação de mulheres em zonas rurais, em seu artigo 14. Com efeito, os Estados devem garantir a realização do direito à alimentação adequada com amparo na igualdade de gêneros e na autonomia feminina ${ }^{60}$. Para tanto, a Diretiva $13.4 \mathrm{da} \mathrm{ONU}^{61}$ recomenda a prioridade às mulheres em programas de segurança alimentar e nutricional, com vistas a reforçar seu papel de tomada de decisões, garantindo que os alimentos sejam empregados em favor das necessidades domésticas ${ }^{62}$.

Nessa perspectiva, o Programa Bolsa Família foi editado no ano de 2003, por meio da Medida Provisória $n^{\circ}$ 132, convertida na Lei $n^{\circ} 10.386 / 2004$. Ele se expandiu pelas regiões mais pobres do país, tendo como objetivos: (i) reduzir a pobreza por meio da transferência de ren-

60 As normas de Direito Privado devem se harmonizar tanto à Constituição, como aos tratados de direitos humanos. Cogita-se, então, de um controle de convencionalidade ou supralegalidade das normas jurídicas internas ao direito humano à alimentação adequada. Cf. CARVALHO, Alexander Perazo Nunes de. Convencionalização do direito civil: a aplicação dos tratados e convenções internacionais no âmbito das relações privadas. Revista de Direito Internacional, Brasília, v. 12, n. 2, p. 342-354, 2015. p. 351. Disponível em: <https://www.publicacoesacademicas.uniceub.br/rdi/article/ view/3756/pdf $>$. Acesso em: 30 jan. 2017.

61 ORGANIZAÇÃO DAS NAÇÕES UNIDAS PARA A ALIMENTAÇÃO E A AGRICULTURA. Diretrizes Voluntárias em apoio à realização progressiva do direito à alimentação adequada no contexto de segurança alimentar nacional. O direito à alimentação. Roma. 2015. p. 28. Disponível em: <http://www.fao.org/3/b-y7937o.pdf>. Acesso em: 30 jan. 2017.

62 SCHUTTER, Oliver de. Droits des femmes et droit à l'alimentation. Rapport sumis par le Rapporteur spécial sur le droit à l'alimentation. Conseil des droits de l'homme. Nations Unies. Assemblée générale, 24 dez. 2012. Disponível em: < http://www.ohchr.org/Documents/ HRBodies/HRCouncil/RegularSession/Session22/A-HRC-22-50_ fr.pdf>. Acesso em: 26 out. 2016. p. 12. 
da familiar e (ii) reforçar o exercício de direitos sociais, como a saúde e a educação, com vistas a romper o ciclo da pobreza. O Programa destina-se às famílias em situação social adversa, com dificuldade de acesso à alimentação adequada, elegendo como critério absoluto a priorização de famílias em situação de vulnerabilidade social: as extremamente pobres com renda mensal inferior a sessenta reais e as moderadamente pobres com renda mensal entre sessenta e cento e vinte reais ${ }^{63}$. Transfere-se às famílias um valor mensal em dinheiro desde que sejam cumpridas certas condições, como manter as crianças em idade escolar na escola e fazer o acompanhamento mensal de saúde e nutrição dessas crianças.

Ao condicionar educação e saúde à segurança alimentar e nutricional, o Bolsa Família expressa e concretiza uma clara visibilidade da condição feminina no contexto familiar no Brasil. Eis que as mulheres são as primeiras beneficiárias do Programa, o que permite lhes atribuir os deveres de manutenção das crianças na escola e de cuidados com a saúde. Nesse aspecto, residem seus resultados positivos como a redução da pobreza, diminuição da disparidade de rendas, maior frequência escolar, cuidados com a vacinação e garantia de que as crianças não serão submetidas ao trabalho ${ }^{64}$.

No entanto, a opção de priorizar as mulheres como beneficiárias do Programa Bolsa Família gera discussões. Vozes proclamam que esta característica reforça a divisão sexual das tarefas no lar e enfraquece a participação das mulheres com o mercado de trabalho. Eis que as beneficiárias teriam menos horas de trabalho e salários menores que outras mulheres que estão no mesmo nível de pobreza, mas não participam do Programa. Após avaliar a relação entre as mulheres beneficiárias do Bolsa Família e o mercado de trabalho, Bila Sorj e Adriana Fontes concluem que:

Tais resultados nos convidam a pensar que se a política de luta contra a pobreza, que é o objetivo do Programa Bolsa Família, mostra uma relativa eficácia, ela não favorece realmente a entrada das mães no mercado de trabalho e não lhes ajuda a encontrar melhores condições de emprego. O $\mathrm{PBF}$, endereçando-se com prioridade às mulheres,

63 SORJ, Bila; FONTES, Adriana. Les politiques publiques au Brésil et l'articulation entre travail et famille. Une comparaison interrégionale. Cabiers du Genre. Paris, v. 1, n. 46, p. 155-176, 2009. Disponível em: <http://www.cairn.info/revue-cahiers-du-genre2009-1-page-155.htm>. Acesso em: 27 out. 2016. p. 164-165.

64 SORJ, Bila.; GAMA, Andréa. Family Policies in Brazil. ROBILA, Mihaela (Coord.). Handbook of family policies across the globe. New York City: Springer, 2014. p. 468. reconhece-lhes, inicialmente, no seu papel familiar e não as incentiva a desenvolver sua autonomia individual $^{65}$.

Trata-se de questionar se tais programas resultariam em uma desigualdade de gênero ${ }^{66}$, pois tenderiam a reforçar a divisão de papéis entre os sexos, por considerar, sobretudo, a proteção dos direitos das mães e das crianças. Eis que semelhante concepção revelar-se-ia restritiva, transpondo para o segundo plano a reivindicação de igualdade entre os sexos, por desconsiderar a mulher como ser humano ${ }^{67}$. Outros identificam o fortalecimento da participação das mulheres no Programa, o que lhes confere maior autoridade no espaço doméstico em razão do aumento do poder de aquisição e recursos para consumo ${ }^{68}$.

Para resolver essa difícil equação, o trabalho analisa as categorias de reconhecimento, redistribuição e representação, problematizadas por Nancy Fraser ${ }^{69}$ e os dados prospectados em pesquisa empírica realizada pelo Ministério do Desenvolvimento Social.

65 Tradução livre de ; "De tels résultats nous invitent à penser que si la politique de lutte conte la pauvreté, qui est l'objectif du Programme Bourse Famille, montre une relative efficacité, elle ne favorise pas réellement l'entrée des mères sur le marché du travail et ne les aide pas à trouver de meilleures conditions d'emploi. Le PBF, en s'adressant en priorité aux femmes, les reconnaît d'abord dans leur rôle familial et ne les incite pas à développer leur autonomie individuelle. » SORJ, Bila; FONTES, Adriana. Les politiques publiques au Brésil et l'articulation entre travail et famille. Une comparaison interrégionale. Cabiers du Genre. Paris, v. 1, n. 46, p. 155-176, 2009. Disponível em: <http://www.cairn.info/revue-cahiers-du-genre2009-1-page-155.htm>. Acesso em: 27 out. 2016. p. 167.

66 SCHUTTER, Oliver de. Droits des femmes et droit à l'alimentation. Rapport sumis par le Rapporteur spécial sur le droit à l'alimentation. Conseil des droits de l'homme. Nations Unies. Assemblée générale, 24 dez. 2012. Disponível em: <http://www.ohchr.org/Documents/ HRBodies/HRCouncil/RegularSession/Session22/A-HRC-22-50_ fr.pdf $>$. Acesso em: 26 out. 2016. p. 12.

67 LE POINT SUR. Le droit à l'alimentation et genre. Roma : FAO L'Organisation des Nations Unies pour l'alimentation et l'agriculture. Unité pour le droit à l'alimentation, 2007. p. 1-2, Disponível em : <http://www.fao.org/3/a-a1610f.pdf>. Acesso em: 06 out. 2016. p. 1.

68 SUÁREZ, Mireya; TEIXEIRA, Marlene (Coord.). O Programa Bolsa Família e o enfrentamento das desigualdades de gênero: o desafio de promover o reordenamento do espaço doméstico e o acesso das mulheres ao espaço público. In: PAES-SOUSA, Rômulo; VAITSMAN, Jeni (Org.). Cadernos de Estudos. Desenvolvimento social em debate. Síntese das pesquisas de avaliação de programas sociais do MDS. 2007. Disponível em; <http://aplicacoes.mds.gov.br/sagirmps/ferramentas/docs/caderno\%20-\%2005.pdf>. Acesso em: 27 out. 2016. p. 22.

69 FRASER, Nancy. Da redistribuição ao reconhecimento? Dilemas da justiça numa era "pós-socialista". Tradução de Júlio Assis Simões. Cadernos de campo, São Paulo, n. 14/15, p. 231-239, 2006. Disponível em: <http://www.revistas.usp.br/cadernosdecampo/ article/view/50109/54229>. Acesso em: 24 out. 2016. p. 236 et seq. 
Os condicionantes estabelecidos pelo Programa Bolsa Família permitem a compreensão da dinâmica da articulação entre os movimentos sociais, o Estado e as políticas públicas. Emergem desta articulação entre o mundo vivido, no qual estão presentes os movimentos sociais ou relações interindividuais, e o sistema, composto pelo Estado e mediado pela esfera pública, demandas por redistribuição, reconhecimento e representação. Nessa seara a segurança alimentar e nutricional está em questão, a partir do olhar da condição feminina na família brasileira. Eis que tais categorias são elementos necessários da constituição da cidadania e dos direitos humanos.

A demanda por redistribuição consiste em dar visibilidade às desigualdades de ordem econômica, expressas na exploração do trabalho, que expropria quem o exerce da possibilidade de acesso ao que produz; na marginalização econômica que impele os trabalhadores a trabalhos que não os satisfazem e/ou que são remunerados de forma inapropriada, não condizente, ou, ainda, na situação extrema que os marginaliza de qualquer possibilidade de trabalho ou de sua inexistência; na privação de um padrão de vida minimamente digno em virtude da precariedade das relações de trabalho.

A dimensão do reconhecimento consiste em dar visibilidade a padrões sociais e culturais de representação, interpretação e comunicação imbuídos de vários tipos de dominação, negação e desrespeito. A dominação cultural que submete sujeitos, em assimetria de poder, a padrões culturais alheios à construção cultural aos quais foram socializados; a negação ou o não reconhecimento de práticas oriundas da construção cultural nativa; e o desrespeito, através da difamação e desqualificação desse padrão cultural não hegemônico.

Finalmente, a representação consiste em abrir espaços de empoderamento, mas não apenas isso. Eis que ele atua em duas frentes: a primeira seria a constituição e/ou ampliação da participação política de grupos minoritários (entendidos aqui como não hegemônicos) em contextos instituídos e consolidados; e a segunda em provocar a constante dinâmica das disputas sobre a justiça para que os limites de contenção nacionais e transnacionais do campo da política e do direito sejam permanentemente avaliados e atualizados.

Com base nas categorias acima referidas, é possível analisar os dados prospectados em pesquisa empírica. De acordo com o CadÚnico (Ministério do Desenvol- vimento Social), no ano de 2016, dos 206.634.867 brasileiros, 22,52\% pessoas são beneficiárias do Programa Bolsa Família. No que tange à distribuição por sexo, entre os beneficiários, $56,62 \%$ são mulheres e esta proporção se repete de forma muito semelhante em todas as regiões ${ }^{70}$. Comparando-se com os dados do Censo 2010, segundo o qual 51\% da população era composta por mulheres, verifica-se, claramente, um perfil mais feminino nas famílias em situação de pobreza ou de extrema pobreza, do que na população em geral.

Essa condição da mulher na sociedade brasileira pode ser explicada pela centralidade da sua condição historicamente construída na unidade doméstica, sempre ligada às atividades de cuidado, zelo e limpeza. No que se refere à unidade doméstica, o padrão cultural histórico da sociedade brasileira reproduz o modelo denominado família nuclear bigeracional ${ }^{71} \mathrm{com}$ funções sociais vinculadas aos laços de afinidades, sendo o casamento um deles, e, ainda, os cuidados da prole e os cuidados com o ambiente doméstico, atribuídos às mulheres.

Os indicadores revelam que as mulheres beneficiárias, em sua maioria titulares do cartão do Bolsa Família, foram adquirindo maior autonomia e poder nas decisões familiares e na compra de bens duráveis, remédios e vestuário, comparativamente às mulheres não beneficiárias. É a sua visibilidade como consumidoras, o que contribui decisivamente para a sobrevivência da família e para o desenvolvimento da economia local. Corrige-se, então, uma injustiça de gênero revelada pela desigualdade econômica, operando a redistribuição.

Esse resultado, também, contribui para que as beneficiárias do Bolsa Família afirmem sua autoridade no espaço doméstico, à medida que são mais respeitadas pelos membros da família por contribuírem com os gastos familiares e a não dependerem do marido ou companheiro. Notam Mireya Suárez e Marlene Libardoni que tal resultado corrobora com as análises que defendem que as mulheres titulares do benefício do Programa Bolsa Família têm ganhos na relação de gênero, à medida que se tornam mais independentes financeiramente dos maridos ou companheiros e com mais autonomia na

70 BRASIL. Ministério do Desenvolvimento Social e Combate À Fome. Relatório de Informaçoes Sociais Bolsa Família e Cadastro Único. Disponível em: <http://aplicacoes.mds.gov.br/sagi-data/METRO/ metro_ds.php?p_id=72>. Acesso em: 31 out. 2016.

71 Tipo ou modelo de família constituído por pai, mãe e filhos. 
alocação de recursos no domicílio ${ }^{72}$. Em um contexto no qual as mulheres não concebem qualquer liberdade para tomar decisões ou alterar posições na hierarquia de gêneros, há o reconhecimento de um padrão cultural de gênero em famílias em situação de pobreza. Mireya Suárez e Marlene Libardoni reconhecem nisto uma mudança e subjetividade individual:

O fortalecimento da identidade feminina é indiscutível porque, como se disse na introdução deste artigo, o Programa Bolsa Família veio fortalecer a condição social de quem, por orientação cultural e subjetividade individual, está posicionada da maneira mais adequada para zelar pelas crianças e de quem assenta seu prestígio no bom desempenho da maternagem ${ }^{73}$.

A participação no Programa também significou uma mudança na percepscão das beneficiárias sobre si próprias como cidadãs, por ocasião da obtenção de documentos como carteira de identidade e certidão de nascimento, ampliando o espaço de existência local, notadamente em áreas rurais. Trata-se de um impacto na representação de cidadania da mulher, “...potencialmente mais marcante que os outros dois [...] porque o conhecimento de ser parte de uma cidadania e a consciência de não a exercer de fato, porque ainda não se tem existência na esfera pública, causa [...] uma reviravolta na subjetividade dessas mulheres" ${ }^{74}$.

Mulheres beneficiárias também têm ampliado sua autonomia na decisão de participar do mercado de trabalho e sobre o uso de métodos contraceptivos, tendências que certamente contribuíram para a expressiva diminuição da fecundidade no Brasil entre 2000 e 2010. Tal fato pode ser verificado, inclusive, entre mulheres de baixa renda, isto é, entre aquelas com renda domiciliar per capita de até $R \$ 70,00$, pois a fecundidade caiu de 5,1 filhos para 3,6 no período.

72 SUÁREZ, Mireya; LIBARDONI, Marlene. O impacto do Programa Bolsa Família: mudanças e continuidades na condição social das mulheres. In: VAITSMAN, J.; PAES-SOUSA, R. (Ed.). Avaliação de politicas e programas do MDS: Resultados. Bolsa Família e assistência social. Brasília: MDS, 2007. p. 143.

73 SUÁREZ, Mireya; LIBARDONI, Marlene. O impacto do Programa Bolsa Família: mudanças e continuidades na condição social das mulheres. In: VAITSMAN, J.; PAES-SOUSA, R. (Ed.). Avaliação de políticas e programas do MDS: Resultados. Bolsa Família e assistência social. Brasília: MDS, 2007. p. 146.

74 SUÁREZ, Mireya; LIBARDONI, Marlene. O impacto do Programa Bolsa Família: mudanças e continuidades na condição social das mulheres. In: VAITSMAN, J.; PAES-SOUSA, R. (Ed.). Avaliação de políticas e programas do MDS: Resultados. Bolsa Família e assistência social. Brasília: MDS, 2007. p. 147.
Esse cenário indica uma vertente de empoderamento de gênero consolidado a partir de uma política pública abrangente, que opera uma agenda universalista, que é a do direito humano e fundamental à alimentação adequada. Mas, moldada por um contexto particular e relativo, no qual os elementos culturais da tradição e do saber local ${ }^{75}$, sobre o papel da mulher na família, configuram como resultante uma nova inserção de status dessas mulheres.

\section{Considerações Finais}

A primeira parte deste trabalho pretendeu retratar a recepção do direito humano à alimentação adequada no contexto de discussão entre universalismo e relativismo. Foi acolhido pela concepção contemporânea de direitos humanos, que expressa indivisibilidade e universalidade na Declaração de 1948 e no Pacto Internacional de Direitos Econômicos, Sociais e Culturais de 1966. O direito humano à alimentação adequada também passa a ser acolhido no plano regional, considerando as diferenças culturais. Esta contraposição, já dissipada pela concepção de direitos humanos como espaços de luta pela dignidade, torna possível conceber aquele direito como um produto cultural que necessita de uma proteção voltada aos grupos mais vulneráveis como as mulheres.

Enfrentando a discussão acerca de uma possível fragmentação entre direitos humanos e direitos fundamentais, a segunda parte deste trabalho optou por considerar o direito humano e fundamental à alimentação adequada com a finalidade de proteção efetiva da pessoa humana. Sua recepção no direito interno, por meio de seu ingresso no rol de direitos sociais do artigo $6^{\circ}$ da Constituição da República de 1988, tem como principal efeito ser objeto de políticas públicas. Quando se volta para a condição feminina estas se revelam como políticas públicas em favor da família. Para tanto, passou-se a examinar o desafio de conciliar o combate à fome com a autonomia da mulher no Programa Bolsa Família.

A terceira parte do trabalho enfrentou as controvér-

75 Segundo Clifford Geertz, o saber local é praticar um "ir e vir hermenêutico entre os dois campos", isto é, a Antropologia e o Direito. Este autor preconiza uma Antropologia interpretativa, situada no relativismo cultural, que permite descobrir princípios gerais em fatos locais GEERTZ, Clifford. O saber local. Novos ensaios em antropologia interpretativa. Traduzido por Vera Mello Joscelyne. Petrópolis: Vozes, 1998. p. 253. 
sias geradas pela prioridade da mulher como beneficiária do Programa Bolsa Família. Recorreu-se às categorias de reconhecimento, redistribuição e representação para avaliar seus impactos. Teve como base em dados empíricos, que apontam um alto percentual de famílias cuja responsável é a mulher e de uma cultura na qual esta não concebe sua liberdade de decisão ou de alterar a hierarquia entre os sexos, conclui-se pelo fortalecimento de sua condição feminina. O Programa Bolsa Família parece responder ao desafio de conciliar o combate à pobreza, à autonomia da mulher, revelando-se como uma vertente de empoderamento de uma agenda universalista, em um contexto relativista.

\section{REFERÊNCIAS}

BEZERRA, Islândia Costa; ISAGUIRRE, Kátya Regina. Direito humano à alimentação adequada (DHAA): a discussão da "geografia da fome" à sua proteção jurídica no Brasil, Revista Pensar, Fortaleza, v. 18, n. 3, p. 675692, set./dez. 2014. p. 677.

BRASIL. Ministério do Desenvolvimento Social e Combate À Fome. Relatório de Informações Sociais Bolsa Família e Cadastro Único. Disponível em: <http://aplicacoes.mds. gov.br/sagi-data/METRO/metro_ds.php?p_id=72>. Acesso em: 31 out. 2016.

CARVALHO, Alexander Perazo Nunes de. Convencionalização do direito civil: a aplicação dos tratados e convenções internacionais no âmbito das relações privadas. Revista de Direito Internacional, Brasília, v. 12, n. 2, p. 342354, 2015. p. 351. Disponível em: < https://www.publicacoesacademicas.uniceub.br/rdi/article/view/3756/ pdf>. Acesso em: 30 jan. 2017.

CASTRO, Josué de. Geografia da fome (O dilema brasileiro: pão ou aço). 10. ed. Rio de Janeiro: Antares, 1984.

COURTIS, Christian. The Right to Food as a Justiciable Right: Challenges and Strategies. BONGDANDY, A. WOLFRUM, R. (Coord.). Max Planck Yearbook of United Nations Law. Local: Koninklije Brill N., 2007. p. 317-337.

FACHIN, Melina Girardi. Fundamentos dos direitos bumanos: Teoria e práxis na cultura da tolerância. Rio de Janeiro: Renovar, 2009.

FACHIN, Melina Girardi. Todos os nomes e um só sentido: a aproximação dos direitos humanos aos direitos fundamentais tendo em vista sua efetivação prática. Revista Brasileira de Direito Internacional, Curitiba, v. 3, n. 3, jan./jun. 2006.

FLORES, Joaquín Herrera. A (re) invenção dos direitos bumanos. Florianópolis: Fundação Boiteux e IDHID, 2009.

FRANÇA, Alexandra Beurlen de. O direito bumano à alimentação adequada no Brasil. 2004. 260 f. Dissertação (Mestrado em Direito) - Programa de Pós-Graduação em Direito, Universidade Federal de Pernambuco, Recife, 2004.

FRASER, Nancy. Da redistribuição ao reconhecimento? Dilemas da justiça numa era "pós-socialista". Tradução de Júlio Assis Simões. Cadernos de campo, São Paulo, n. 14/15, p. 231-239, 2006. Disponível em: $<$ http://www.revistas.usp.br/cadernosdecampo/article/view/50109/54229>. Acesso em: 24 out. 2016.

GEERTZ, Clifford. O saber local. Novos ensaios em antropologia interpretativa. Traduzido por Vera Mello Joscelyne. Petrópolis: Vozes, 1998.

Golay, Christophe; ÖZDEN, Melik. Le droit à l'alimentation. Un droit humain fondamental stipulé par l'ONU et reconnu par des traités régionaux et de nombreuses constitutions nationales. Une collection du Programme Droit Humains du Centre Europe - Tiers Monde (CETIM) . Disponível em : < http://www.eoi.at/d/ EOI\%20-\%20Jahresberichte/Monaco/bro1-alim-A4fr.pdf>. Acesso em: 06 out. 2016.

IBGE. Estatísticas de gênero. Uma análise dos resultados do censo demográfico 2010. Disponível em: < http:/ / biblioteca.ibge.gov.br/visualizacao/livros/liv88941. pdf $>$. Acesso em: 25 out. 2016.

KLEBA, Maria Elisabeth; WENDAUSEN, Agueda. Empoderamento: processo de fortalecimento dos sujeitos nos espaços de participação social e democratização política. Saúde e sociedade, São Paulo, v. 18, n. 4, p. 733743, 2009. Disponível em: < http:/ /www.scielo.br/pdf/ sausoc/v18n4/16.pdf>. Acesso em: 29 out. 2016.

LAFER, Celso. A reconstrução dos direitos humanos. Um diálogo com o pensamento de Hannah Arendt. São Paulo: Companhia das Letras, 2009.

LE POINT SUR. Le droit à l'alimentation et genre. Roma : FAO L'Organisation des Nations Unies pour l'alimentation et l'agriculture. Unité pour le droit à l'alimentation, 2007. p. 1-2, Disponível em : <http://www.fao. org/3/a-a1610f.pdf>. Acesso em: 06 out. 2016. 
LUÑO, António E. Pérez. Los derechos fundamentales. 10. ed. Madrid: Editorial Tecnos, 2011. (Temas clave de la Constituicion española).

MÜLLER, Marcela. O direito social fundamental à alimentação adequada e sua proteção no contexto das organizações internacionais. 2014. 143 f. Dissertação (Mestrado em Direito) - Programa de Pós-Graduação em Direito, Universidade de Itaúna, Itaúna, 2014.

NIVARD, Carole. Le droit à l'alimentation. La Revue des Droits de l'Homme, jun. 2012. Disponível em: < http:// revdh.files.wordpress.com/2012/06/le-droit-c3a0-lalimentation.pdf>. Acesso em: 06 out. 2016.

ORGANIZAÇÃO DAS NAÇÕES UNIDAS PARA A ALIMENTAÇÃO E A AGRICULTURA. Diretrizes Voluntárias em apoio à realização progressiva do direito à alimentação adequada no contexto de segurança alimentar nacional. O direito à alimentação. Roma. 2015. p. 28. Disponível em: <http://www.fao.org/3/b-y7937o.pdf>. Acesso em: 30 jan. 2017.

PEREIRA, Potyara A. P. Discussões conceituais sobre política social como política pública e direito de cidadania. In: BOSCHETTTI, Ivanete et al. (Org.). Política Social no Capitalismo: tendências contemporâneas. São Paulo: Cortez, 2009.

PIOVESAN, Flávia. A universalidade e a indivisibilidade dos direitos humanos: desafios e perspectivas. In: BALDI, César Augusto (org.). Direitos humanos na sociedade cosmopolita. Rio de Janeiro: Renovar, 2004. p. 45-71.

PIOVESAN, Flávia. Direitos humanos e o direito constitucional internacional. 12. ed. São Paulo: Saraiva, 2011.

PRATA, Ana. A tutela constitucional da autonomia privada. Coimbra: Almedina, 1982.

SCHUTTER, Oliver de. Droits des femmes et droit à l'alimentation. Rapport sumis par le Rapporteur spécial sur le droit à l'alimentation. Conseil des droits de l'homme. Nations Unies. Assemblée générale, 24 dez. 2012. Disponível em: <http://www.ohchr.org/Documents/
HRBodies/HRCouncil/RegularSession/Session22/AHRC-22-50_fr.pdf>. Acesso em: 26 out. 2016.

SORJ, Bila.; GAMA, Andréa. Family Policies in Brazil. ROBILA, Mihaela (Coord.). Handbook of family policies across the globe. New York City: Springer, 2014. p. 459471.

SORJ, Bila; FONTES, Adriana. Les politiques publiques au Brésil et l'articulation entre travail et famille. Une comparaison interrégionale. Cabiers $d u$ Genre. Paris, v. 1, n. 46, p. 155-176, 2009. Disponível em: <http:// www.cairn.info/revue-cahiers-du-genre-2009-1-page-155.htm>. Acesso em: 27 out. 2016.

SUÁREZ, Mireya; LIBARDONI, Marlene. O impacto do Programa Bolsa Família: mudanças e continuidades na condição social das mulheres. In: VAITSMAN, J.; PAES-SOUSA, R. (Ed.). Avaliação de políticas e programas do MDS: Resultados. Bolsa Família e assistência social. Brasília: MDS, 2007.

SUÁREZ, Mireya; TEIXEIRA, Marlene (Coord.). O Programa Bolsa Família e o enfrentamento das desigualdades de gênero: o desafio de promover o reordenamento do espaço doméstico e o acesso das mulheres ao espaço público. In: PAES-SOUSA, Rômulo; VAITSMAN, Jeni (Org.). Cadernos de Estudos. Desenvolvimento social em debate. Síntese das pesquisas de avaliação de programas sociais do MDS. 2007. Disponível em; <http:/ / aplicacoes.mds.gov.br/sagirmps/ferramentas/docs/ caderno\%20-\%2005.pdf>. Acesso em: 27 out. 2016.

VALENTE, Flávio Luiz Schieck. Fome, desnutrição e cidadania: inclusão social e direitos humanos. Saúde e sociedade, São Paulo, v. 12, n. 1, p. 51-60, jan./jun., 2003.

VILLELA, João Baptista. Liberdade e família. Monografia (TCC) - Faculdade de Direito da UFMG, Belo Horizonte 1980.

VILLEY, Michel. O direito e os direitos humanos. São Paulo: M. Fontes, 2007. 
Para publicar na Revista de Direito Internacional, acesse o endereço eletrônico www.rdi.uniceub.br ou www.brazilianjournal.org.

Observe as normas de publicação, para facilitar e agilizar o trabalho de edição. 